\title{
The Effects of Rational and Experiential Information Processing of Expert Testimony in Death Penalty Cases
}

\author{
Daniel A. Krauss, J.D., Ph.D.,* \\ Joel D. Lieberman, Ph.D. ${ }^{\dagger}$ \\ and Jodi Olson, M.A. ${ }^{\dagger}$
}

\begin{abstract}
Past research examining the effects of actuarial and clinical expert testimony on defendants' dangerousness in Texas death penalty sentencing has found that jurors are more influenced by less scientific pure clinical expert testimony and less influenced by more scientific actuarial expert testimony (Krauss \& Lee, 2003; Krauss \& Sales, 2001). By applying cognitive-experiential self-theory (CEST) to juror decision-making, the present study was undertaken in an attempt to offer a theoretical rationale for these findings. Based on past CEST research, 163 mock jurors were either directed into a rational mode or experiential mode of processing. Consistent with CEST and inconsistent with previous research using the same stimulus materials, results demonstrate that jurors in a rational mode of processing more heavily weighted actuarial expert testimony in their dangerousness assessments, while those jurors in the experiential condition were more influenced by clinical expert testimony. The policy implications of these findings are discussed. Copyright $(C) 2004$ John Wiley \& Sons, Ltd.
\end{abstract}

\section{INTRODUCTION}

Since the landmark United States Supreme Court decision in Barefoot v. Estelle (1983), upholding the constitutionality of a Texas death sentence based on several mental health practitioners' predictions of the defendant's future dangerousness, it has been widely recognized that it is constitutional for experts to offer such testimony even if that testimony is often unreliable. At issue in the Barefoot case were the pronouncements of a prosecution psychiatrist who did not interview the

\footnotetext{
*Correspondence to: Daniel A. Krauss, J.D., Ph.D., Department of Psychology, Claremont McKenna College, 850 Columbia Avenue, Claremont, CA 91711, U.S.A. E-mail: Dkrauss@claremontmckenna.edu $\dagger$ University of Nevada, Las Vegas.
} 
defendant, but believed that there was " $100 \%$ and absolute chance" that the defendant would continue to be dangerous. ${ }^{1}$ This testimony was deemed constitutional by the court even though the existing studies of mental professionals' ability to predict dangerousness suggested that such predictions were wrong two out of three times (Brief for the American Psychiatric Association as Amicus Curiae, in Barefoot v. Estelle, citing Monahan 1981, who, in his review of five studies on this topic, found error rates between 65 and $85 \%$ for such predictions). In the end, the court reasoned that "we are not persuaded that such testimony is always unreliable and that the fact-finder and the adversary will not be competent to uncover, recognize, and take due account of its shortcoming" (Barefoot v. Estelle, p. 893).

Following the Court's decision in Barefoot, mental health practitioners' predictions of dangerousness have come to play an even greater role in legal proceedings, from civil commitment of mentally ill individuals (e.g. O'Connor v. Donaldson, 1975) to more recent post-jail detention of sexual predators (e.g. Kansas v. Hendricks, 1997; Kansas v. Crane, 2002). Critics within the legal and psychological fields have questioned the ethics (Faust \& Ziskin, 1988; Lavin \& Sales, 1998), the validity (Cunningham \& Reidy, 1999, 2002; Edens, Petrila, \& Buffington-Vollum, 2001), and the biasing effects that these potentially unreliable expert predictions might have on jury decisions (Guy \& Edens, 2003; Krauss \& Lee, 2003; Krauss \& Sales, 2001). Although considerable advances have been made in the area of dangerousness prediction or risk assessment validity (see, e.g., Quinsey, Harris, Rice, \& Cormier, 1998; Webster, Douglas, Eaves, \& Hart, 1997), there still remains considerable doubt whether these new procedures are being used in actual practice (see, e.g., Melton, Petrila, Poythress, \& Slobogin, 1997). Moreover, the court's assumptions in Barefoot that jury members and adversary procedures will be adequate to undo any bias caused by less scientific expert opinions has not been borne out by the limited research that has investigated these issues (e.g. Krauss \& Sales, 2001). In fact, three studies that have directly investigated this question have found that jurors are more influenced (Krauss \& Lee, 2003; Krauss \& Sales, 2001, in a Texas death penalty case) or at least equally influenced (Guy \& Edens, 2003, in a Texas sexual predator law case) by less scientifically valid clinical predictions of dangerousness when this less scientific method of assessing dangerousness was compared with more scientifically valid expert testimony. Unfortunately, the method by which different types of expert testimony may affect jury decisions is poorly understood and not well studied.

Given the significant liberty interest at stake in cases in which mental expert testimony on a defendant's dangerousness is proffered (e.g. execution in Texas and 21 other states (Cunningham \& Reidy, 1998), or potential life detention in the 16 jurisdictions with sexually violent predator laws (Krauss \& O’Connor, 2003)) and

\footnotetext{
${ }^{1}$ Under Texas law, at that time, in order for a defendant to receive the death penalty, three special sentencing instructions needed to be answered unanimously beyond a reasonable doubt by a sentencing jury in the affirmative (Tex. Crim. Proc. Code, Art. 370.071b, 1976). These questions were (a) whether the conduct of the defendant that caused the death of the deceased was caused deliberately and with the reasonable expectation that the death of the deceased or another would result, (b) if raised by the evidence, whether the conduct of the defendant was unreasonable in response to provocation, if any, by the deceased, and (c) whether there was a probability that that the defendant would commit criminal acts of violence that represented a continuing threat to society (Texas Crim. Proc. Code, Art 3701b, 1976). The only issue before the Court in the Barefoot case was the third requirement of the Texas death penalty sentencing instruction (Krauss \& Sales, 2001).
} 
the poor scientific quality of such expert testimony in practice, it is clear that more research needs to be performed on the effects of both more and less scientifically valid expert testimony in these cases. This study was undertaken to add to the existing literature on this phenomenon, and to test a potential explanatory theory, cognitive-experiential self-theory (CEST), that may offer insight into why jurors may prefer, or at least are more influenced by, less scientific expert testimony in these decisions. Before turning to the methods, however, it is first necessary to briefly examine advances in the field of risk assessment and examine the existing research that has explored the mechanisms by which mental health professionals' expert testimony on future dangerousness affects juror decisions.

\section{Advances in Risk Assessment}

Although a large body of research demonstrates that "pure" clinical predictions of dangerousness ${ }^{2}$ (i.e. the type of the prediction offered by the expert psychiatrist in the Barefoot case) are unreliable (Grisso \& Appelbaum, 1992; Faust \& Ziskin, 1988; Hart, Webster, \& Menzies, 1993; Melton et al., 1997; Monahan, 1981; Monahan \& Steadman, 1994; Otto, 1992; Showalter, 1990), more recent research suggests they are not as inaccurate as was portrayed in the Barefoot case (Mossman, 1994; his meta-analysis suggests false positive rates closer to $44 \%$ ), and clinical predictions may be equal to other methods of dangerousness prediction for very short time periods (McNeil, Sanders, \& Binder, 1998; Mossman, 1994).

In making long-term predictive judgments, however, pure clinical decisionmakers are inaccurate for a number of reasons. Reasons for mental health practitioners' errors include such problems as (a) ignoring base rate information (the failure to take into account the normal level at which an event is likely to occur), (b) assigning non-optimal weights to factors (combining factors in manner that is subjectively appealing rather than empirically derived), and (c) employing the representativeness heuristic (the tendency to make decisions or judge information in a manner that fits our preconceived categories or stereotypes of a situation) (Grove \& Meehl, 1996; Krauss, 2004; Tversky \& Kahneman, 1982). For example, a mental health professional might place excessive weight on the heinousness of the defendant's most recent act (i.e. ignoring the base rate, assigning a non-optimal weight to this factor, and utilizing the representativeness heuristic) in arriving at a conclusion that the defendant will be dangerous in the future. As a result of these errors, for the long-term predictions of dangerousness required by the Texas death penalty statute as well as most jurisdictions' sexually violent predator laws, clinical predictions have been demonstrated to be uniformly inferior to other means of violence prediction (see, e.g., Borum, 1996; Gardner, Lidz, Mulvey, \& Shaw, 1996; Mossman, 1994; Quinsey et al., 1998).

Actuarial predictions of dangerousness are one of the most common methods of risk prediction that have demonstrated superiority over pure clinical predictions in head to head comparisons (see, e.g., Gardner et al., 1996, and Harris, Rice, \& Cormier, 2002, for two studies, but see Litwack (2001) for why these comparisons

\footnotetext{
${ }^{2}$ For purposes of this article, "pure" clinical predictions refer to predictions based solely on a mental health professional's judgment and not on validated or recognized risk assessment tools.
} 
may have been lacking). Actuarial prediction instruments are created from empirically verified risk factors (e.g. past history of violence, psychopathic personality, prior arrests), which have been demonstrated to predict the appropriate outcome for the population being studied (Monahan \& Steadman, 1994). These risk factors are then statistically combined in a manner that maximizes their ability to predict the intended outcome. The Violence Risk Appraisal Guide (VRAG) ${ }^{3}$ represents an actuarial instrument that has shown considerable success in the prediction of future violence (Borum, 1996; Rice \& Harris, 1995). A number of studies have indicated that it has classification accuracy close to $75 \%$ for violent offenders (e.g. Harris et al., 2002). ${ }^{4}$

Actuarial prediction instruments have, however, also received criticism from researchers and scholars (e.g. Melton et al., 1997; Monahan et al., 2001). Critics have questioned these instruments' generalizability, their failure to incorporate very rare but important risk factors (i.e. factors that would not be relevant to large population of offenders but might be especially significant to particular cases (e.g. paraplegia)), and their failure to include risk reducing or protective factors (e.g. a supportive family) (Monahan, 2003).

Based on these concerns, some researchers have developed risk assessment instruments that combine the benefits of actuarial instruments with the flexibility of clinical judgment. Risk assessment tools that utilize these methods are sometimes referred to as guided professional judgments or aide-memoires (Webster et al., 1997). These risk assessment methods utilize risk factors that have been empirically demonstrated to be linked to risk in the empirical literature, but these tools do not suggest how each of these factors should be combined for clinicians to arrive at their final decision. The HCR-20 represents one example of the guided clinical judgment approach, and is specifically designed to assess risk of future violence. It consists of a checklist of 20 items, 10 assessing past or "Historical" factors related to risk, 5 assessing present risk "Clinical" risk factors, and 5 assessing future "Risk" factors. Each item is scored 0 (absent), 1 (possibly or partially present), or 2 (definitely present). Based on the scoring of the 20 items, the practitioner is supposed to offer a statement concerning whether the assessed individual is low, medium, or high risk (Webster et al., 1997). Research investigating the efficacy of the HCR-20 has found promising results (e.g. Borum, 1996; Douglas \& Webster, 1999; Douglas, Ogloff,

\footnotetext{
${ }^{3}$ The Violence Risk Appraisal Guide (VRAG), which was relied upon in one of our experimental conditions in this study, consists of 12 variables (The Hare Psychopathy Checklist (PCL-R), elementary school maladjustment, age of present offense, diagnosis of personality disorder (DSM-III), separation from parents under the age of 16, failure in prior conditional release, criminal history for property offenses, marital status, diagnosis of schizophrenia (DSM-III), victim injury in present offense, history of alcohol abuse, and female victim in present offense). The VRAG was normed on 618 men who committed at least one serious offense, and who were followed for ten years ( $31 \%$ committed a violent act over this time). It accurately predicted dangerousness in $74 \%$ of the cases and demonstrated an AUC $=0.76$, $R=0.44$, sensitivity $=60 \%$, and specificity $=78 \%$ at a 10 point cut-off (Rice $\&$ Harris, 1995). It was revalidated on 868 men possessing similar characteristics and results were substantially the same: clinical accuracy $=70 \%, \mathrm{AUC}=0.74$, sensitivity $=62 \%$, and specificity $=72 \%$ at a 10 point cut-off (Rice \& Harris, 1995).

${ }^{4}$ In addition to the VRAG, a number of other actuarial instruments have been developed to predict a defendant's future dangerousness. For example, high predictive accuracy of a civilly committed populations' violent acts was achieved by an actuarial instrument which used an iterative classification tree approach. This methodology breaks down individuals into groups based on the factors that best discriminate between recidivators and non-recidivators, so that a progressive two by two branching of risk factors and individuals into lower and higher risk groups occurs (Monahan et al., 2001).
} 
Nicholls, \& Grant, 1999). Additionally, it is becoming more common for clinicians to utilize the HCR-20 in their risk assessments (Webster et al., 1997).

Yet, the same criticisms that have been leveled against pure clinical predictions also have bearing on guided clinical judgments. In particular, errors associated with assigning non-optimal weights to factors and combining factors in a manner that is subjectively appealing rather than empirically derived represent significant problems for this method of assessment. This and other problems have led some scholars to suggest that guided clinical judgments are unlikely to be the equals of well validated actuarial predictions of dangerousness (Quinsey et al., 1998).

Some scholars have also questioned the use of actuarial or guided clinical judgment instruments in the future dangerousness predictions required by Texas's death penalty statute (e.g. Cunningham \& Reidy, 1999, 2002). They argue that the "society" these defendants should be assessed as a "danger to" should be prison society because that is where they will be housed for at least 40 years and perhaps indefinitely, ${ }^{5}$ and that neither the HCR-20 nor the VRAG are validated for such an assessment. Instead, they contend that statistical base rate information based on existing data on death-sentenced inmates' prison misconduct is the most appropriate tool for these evaluations (Cunningham \& Reidy, 1999, 2002). ${ }^{6}$ Texas as well as some other jurisdictions have, however, failed to completely adopt this circumspect definition of "danger to society," allowing jurors to define for themselves what "danger to society" means (see, e.g., Smith v. State, 1995).

Although past research (Krauss \& Lee, 2003; Krauss \& Sales, 2001) has compared the influence of expert testimony based on actuarial instruments to pure clinical judgments, we know of no research to date that has also examined a guided professional judgment risk assessment tool and its influence on juror decision-making. Given the increased use of such instruments, this is an oversight in need of correction.

\section{Expert Testimony and Juror Decision-Making}

A multitude of studies have demonstrated that jurors' final decisions are strongly influenced by expert psychological testimony when it is presented on a wide variety of psycho-legal issues from the inaccuracy of eyewitness identification (e.g. Cutler, Penrod, \& Dexter, 1989; Loftus, 1986) to insanity (e.g. Rogers, Bagby, \& Chow, 1992; Rogers, Bagby, Crouch, \& Cutler, 1990). This effect has been demonstrated in both naturalistic experiments (e.g. Sundby, 1997; Shuman, Whitaker, \& Champagne, 1994) and laboratory-based designs (e.g. Brekke \& Borgida, 1988). Although jury decisions are clearly affected by such testimony, the manner in which expert testimony influences jury decisions has received far less attention.

With regard to juror decisions in capital sentencing, several mock juror simulations using the same stimulus materials but employing different populations in different

\footnotetext{
${ }^{5}$ Life imprisonment without parole for 40 years is currently the alternative punishment to death for an offender convicted of capital murder in Texas (Tex. Code Crim. Proc. Ann. art. 37.071(g) (West 2004)). ${ }^{6}$ In fact, a recent survey conducted by Texas Defender Services of 155 death-sentenced inmates suggested that these inmates rarely engaged in prison conduct that resulted in serious injury, and as a result, predictions of their dangerousness by juries were wrong $95 \%$ of the time (Texas Defender Services, 2004).
} 
settings (one involved proceedings occurring in a courtroom while another used a classroom), and using different procedures (one study allowed jurors to deliberate), demonstrated that juror affinity for clinical expert testimony over actuarial expert testimony exists even after the presentation of cross-examination and competing experts (Krauss \& Lee, 2003; Krauss \& Sales, 2001). Interestingly, a study by Guy and Edens (2003) examining the effects of actuarial and clinical predictions of dangerousness on juror decisions in a sexually violent predator case found nonsignificant differences between the two expert testimony conditions. ${ }^{7}$ These results suggest that the strength of juror bias in favor of less scientific clinical expert testimony over more scientific actuarial expert testimony may depend on the context in which the expert testimony is offered (i.e. death penalty sentencing versus sexually violent predator civil commitment). Nevertheless, the existing, albeit limited, empirical research on expert testimony and juror dangerousness decisions uniformly indicates that jurors may overvalue pure clinical predictions of dangerousness because jurors have granted them more or similar weight to more scientific testimony.

\section{Models of Juror Decision-Making}

Although multiple psychological theories suggest why expert testimony may be overvalued by jurors, several heuristic models of persuasion have been offered as the primary reason why certain types of expert testimony exert more influence on jurors' decisions than others. Heuristic persuasion theories ${ }^{8}$ generally suggest that the influence of a message is usually a product of the quality of the argument and the persuasiveness of the substance of the message (i.e. central processing of the information) (Golberg, 1968; Petty \& Caccioppo, 1986). However, when the message is complex or difficult to comprehend, individuals rely on cognitive shortcuts or heuristics to evaluate the value of the communication (Chaiken, 1987; Petty \& Caccioppo, 1986). They are also likely to engage in peripheral processing as opposed to central processing of a message, and as a result rely on means other than the content of the message to decide how much weight to place on expert testimony in their decision-making.

In the courtroom, due to expert testimony's complexity or jurors' pre-existing willingness to rely on the opinion of experts, heuristic methods have been suggested as the means jurors use to evaluate and weigh this testimony (Cooper, Bennett, \& Sukel, 1996; Schuller \& Vidmar, 1992). Unfortunately, heuristic processing models do not fully explain why clinical expert testimony would be valued more than actuarial expert testimony in decision-making. For example, the model does not

\footnotetext{
${ }^{7}$ The Guy and Edens (2003) study utilized somewhat different methodology, however, and the influence of the expert testimony may have been masked by the fact that they simply compared juror overall verdicts and did not examine changes in the jurors' confidence from a baseline condition based on a summary of the case as was the case in the Krauss and Lee (2003) and Krauss and Sales (2001) studies. In addition, the Guy and Edens study evidenced greater uniformity in overall decisions (more verdicts in favor), and the effects of expert testimony may be greatest when there are more ambiguous decisions to be made by jurors.

${ }^{8}$ There are multiple heuristic models (e.g. Chaiken's heuristic model of persuasion and the elaboration likelihood model of Petty and Caccioppo). Since the models offer similar predictions concerning expert testimony and the manner in which it is processed, however, these various theories will be discussed as a single model.
} 
indicate exactly when one processing mode will be used over the other or how difficult information will have to be before the peripheral processing mode is utilized. An alternative dual-process model known as cognitive-experiential self-theory (CEST) (Epstein, 1994; Epstein \& Pacini, 1999) may provide a better understanding of the appeal of intuitive as opposed to more analytically based judgments.

\section{Cognitive-Experiential Self-Theory}

According to CEST (Epstein, 1994; Epstein \& Pacini, 1999) information is processed by two partially independent systems, known as an experiential and a rational mode. The experiential mode is " a crude system that automatically, rapidly, effortlessly, and efficiently processes information" (Epstein, 1994, p. 715) that is intimately associated with affect. It is a very gut-level, emotionally based system that is efficient and requires minimal effort. Thus, it serves as a default mode and is used most of the time. The second system, known as the rational mode, "is a deliberative, effortful, abstract system" (p. 715), that operates at the conscious level, and is analytic, intentional, and relatively affect free. It is "experienced actively and consciously, and requires justification via logic and evidence" (p. 711). CEST maintains that behavior ultimately varies along a continuum between these two systems, and is influenced by the relative contributions of each (Donovan \& Epstein, 1997). A combination of individual differences and situational demands (Denes-Raj \& Epstein, 1994) determines whether behavior is primarily controlled by the experiential or rational systems.

A series of studies has demonstrated that the rational-experiential distinction is useful for understanding social behavior in a variety of contexts. For example, CEST has been used to predict when participants will rely upon a variety of heuristic cues identified by Tversky and Kahneman (Kahneman \& Tversky, 1982; Tversky \& Kahneman, 1974, 1982). Experiential mode processing leads individuals to utilize cues such as the representativeness and availability heuristics, producing errors in probability judgments. However, when participants are first motivated to process information in a rational mode, reliance upon heuristic cues is reduced and more effortful and accurate judgments occur (for a review, see Epstein \& Pacini, 1999).

Experiential processing also produces a strong tendency for individuals to use capricious and limited information to generate broad and holistic impressions of targets (e.g. being a good or bad person). Such judgments are less likely to occur when individuals adopt a rational perspective (Epstein \& Pacini, 1999). Interestingly, participants in CEST studies have indicated that, although they are aware that their reactions in the experiments are not rational, they believed that (like most people) they would still behave that way in real life (Epstein, 1994).

CEST has also been used to understand a variety of clinical and social psychological phenomena, including understanding situations where depressive realism is likely to operate (Pacini, Muir, \& Epstein, 1998), predicting conditions where individuals will prefer either self-enhancing or self-verifying feedback (Morling \& Epstein, 1997), and predicting when displaced aggression is likely to occur (Lieberman \& Greenberg, manuscript submitted for publication). Finally, Lieberman (2002) has recently applied CEST to jury decision-making. In that study, extra-legal biases were shown to be operative when participants were in an 
experiential mode, but not in a rational mode. More specifically, experientially induced participants treated attractive defendants more leniently than unattractive defendants. However, rational participants were more objective in their evaluation of trial evidence, and were not influenced by the defendant's appearance.

\section{The Present Study}

Cognitive-experiential self-theory (CEST) provides a useful theoretical explanation for previous findings regarding the relative influence of different types of expert testimony on jurors'dangerousness assessments. The VRAG requires risk factors to be statistically combined in a manner that maximizes their ability to predict the intended outcome, and expert testimony based on this instrument is clearly analytically oriented. On the other hand, clinical testimony is based more upon the intuition of the expert and the expert's gut-level opinions regarding the potential dangerousness of the defendant. Further, CEST maintains that the experiential system is the default information-processing mode. Thus, CEST would predict that unless participants are induced to adopt the more effortful rational mode that requires logic and evidence to justify conclusions, clinical expert testimony should be particularly persuasive. Such is the pattern of findings in extant research that has shown clinical testimony to be more influential than actuarial testimony. ${ }^{9}$ Jurors induced to think primarily in a rational mode, however, should find actuarial testimony to be more appealing and persuasive than clinical testimony. Using stimulus materials that had previously shown a consistent advantage for clinical expert testimony over actuarial expert testimony, it was hypothesized that inducing a rational mode of processing could reverse these effects. It was also thought that jurors induced into an experiential processing mode would evidence the highest dangerousness ratings following the clinical expert testimony while the jurors induced into a rational model would demonstrate the highest dangerousness ratings following the actuarial expert testimony. In addition, the effect of expert testimony based upon the HCR-20, which combines clinical and actuarial approaches, was also examined. No specific predictions were made with regard to HCR-20 expert testimony other than that this testimony's mixed content would make it less susceptible to the manipulations undertaken and their influence.

\section{METHOD}

\section{Participants}

One hundred and sixty-three psychology and criminal justice undergraduate students from the University of Nevada, Las Vegas, and Claremont McKenna

\footnotetext{
${ }^{9}$ Krauss and Sales (2001) found that actuarial testimony was rated as more influential, credible, and scientifically based, yet it was still less influential on sentencing decisions than clinical testimony. Moreover, Krauss and Sales (2001) and Krauss and Lee (2003) also found that jurors were unaware of their bias in favor of clinical expert testimony. These results parallel the previously mentioned CEST findings that when individuals are in an experiential mode, they are prone to making illogical judgments, they are often unaware of biases that led to these judgments, and even if made aware of their biases, they will continue to follow them despite knowing better (Epstein, 1994).
} 
College participated in the study. Participants took part in the study as one of a number of options for the partial fulfillment of their department's research requirement or for extra credit in their class. The sample consisted of 70 males, 90 females, and 3 people of unreported gender. The average age of participants was 21 . Fiftyeight percent classified themselves as Caucasian, $8 \%$ as African-American, $12 \%$ as Asian, $6 \%$ as Hispanic, $14 \%$ as "other," and 3\% did not indicate their race. Twentynine percent reported that their political affiliation was Republican, 25\% said they were Democrats, $7 \%$ were Independents, $11 \%$ were affiliated with other groups, and $29 \%$ did not report affiliation with any political group. In general, participants reported having moderately strong political beliefs $(M=5.1$ on a scale range from 1 [not very strong] to 10 [very strong]), and expressed support for the death penalty $(M=3.6$ on a scale range from -10 [oppose death penalty] to 10 [favor death penalty]). Twenty percent of the sample reported having prior experience as a juror. In each experimental session, between 1 and 5 participants were randomly assigned in a 2 (processing mode: rational versus experiential) $\times 3$ (expert testimony: clinical versus actuarial versus HCR) between subjects design. All participants were assured of the anonymity of their responses. This study was conducted in accordance with the current ethical principles of the APA.

\section{Procedure}

An experimenter, who was blind to conditions, introduced the study's purpose as an examination of the relationship between personality characteristics and jury decision-making. Following initial instructions, the experimenter directed participants into private cubicles to complete their materials. Participants were also "death qualified" based on the requirements of Wainwright v. Witt (1985). Jurors who were unable to consider the death penalty as a punishment option in a particular case because of their opposition to capital sentencing in general were excused from the remainder of the experiment.

Participants were given an initial packet that contained several personality questionnaires designed to enhance the credibility of the cover story. They were then given background information and sentencing instructions for a capital murder case. The background information supplied included: a summary of the case against the defendant, the defendant's confession, a list of the defendant's prior offenses, and instructions for sentencing the defendant (further explanation of these initial stimulus materials can be found in Krauss and Sales (2001)). After the presentation of the first packet, participants rated their beliefs concerning the defendant's dangerousness and their confidence in their rating of dangerousness (described in detail below).

\section{Processing Mode}

Participants then received a second packet of materials that contained the processing mode (PM) manipulation. They were told that the exercise was part of a personality assessment related to the experiment they were participating in. The processing mode manipulation in this study was designed to create a mindset in 
participants, either rational or experiential. The participants in the rational PM group received a sheet of math problems with instructions to solve various equations and a pad of paper for calculations. Presumably, working on math problems requires analytic thought (Epstein, 1994; Pacini \& Epstein, 1999). Participants who were assigned to the experiential PM were given a task that required them to express their current emotional state. More specifically, participants were told "that feelings and attitudes can be expressed through a number of measures including creative expression. We would like you to draw a picture that describes your gut-level feelings about your emotional state right now." As previously noted, CEST maintains that the experiential system is intimately associated with affect. Participants were given a pack of crayons to draw with. The crayons weighed the same as the pad of paper in the rational condition, and the materials were distributed in large manila envelopes, enabling the experimenter to remain blind to participants' conditions. During debriefing, participants were asked to provide their reactions to this exercise. Participants indicated that they believed the cover story explanation that the processing mode manipulation was an additional personality test.

\section{Expert Testimony}

The third packet that participants received included a trial transcript that contained one of three expert testimonies: actuarial, clinical, or HCR-20. The expert testimony materials were adapted from the Krauss and Sales (2001) study, and the descriptions of the stimulus materials are taken from the same study. The expert testimony was designed to be easily comprehensible to prevent the possibility that the actuarial expert testimony was more complex then the testimony presented in other conditions. In all three expert testimony conditions, the expert also opined that there "... was a high probability that the defendant would be a future danger to society," and simply offered different rationales for this conclusion.

\section{Clinical Opinion Expert}

The clinical opinion expert testimony and expert were modeled on actual experts and expert testimony offered in Texas. The expert testimony consisted of statements of (a) his experience and education, (b) his interview of the defendant, (c) his opinion that the defendant is a severe sociopath, and (d) his belief based on his years of experience that the defendant definitively represents a continuing danger to society. This identical expert and qualifications were used in all conditions.

\section{Expert Actuarial Testimony}

This expert testimony consisted of statements of (a) his experience and education, (b) his interview of the defendant and his description of the VRAG assessment instrument, (c) his use of VRAG with the criminal defendant, and (d) his belief based on the VRAG that the defendant represents a continuing danger to society. 


\section{Expert Guided Professional Fudgment Testimony}

This expert testimony consisted of statements of (a) his experience and education, (b) his interview of the defendant and his description of the HCR-20 assessment instrument, (c) his use of the HCR-20 with the criminal defendant, and (d) his belief based on the HCR-20 that the defendant represents a continuing danger to society.

\section{Cross-Examination}

Following the presentation of the expert testimony, participants read a crossexamination relevant to the expert that gave the testimony. This cross-examination was also identical to the "effective" cross-examination conditions in Krauss and Sales (2001) with a cross-examination condition created for the HCR-20 condition in this experiment.

\section{Cross-Examination of the Clinical Opinion Expert}

The cross-examination of the clinical expert detailed that (a) the dangerousness predictions made by clinicians are often wrong, (b) there is a consensus of experts in dangerousness prediction that clinicians have no special ability to predict dangerousness, (c) the testifying expert had not received any special training in dangerousness prediction, (d) clinical opinions tend to overestimate future violence and are often based on faulty reasoning, (e) the testifying expert was unaware of the base rates of violence for this criminal population, ( $f$ ) actuarial techniques of dangerousness assessment have shown greater validity than clinical instruments, and $(\mathrm{g})$ the confidence the testifying expert has in his opinion has not been linked to accuracy in long-term dangerousness predictions.

\section{Cross-Examination of the Actuarial Expert}

The cross-examination condition of the actuarial expert questioned (a) the use of the VRAG on a population on which it is not validated, (b) the error rate of the instrument, and (c) the failure of the VRAG instrument to take into account casespecific information or protective factors.

\section{Cross-Examination of the Guided Professional Fudgment Expert}

The cross-examination condition of the guided professional judgment expert questioned (a) the possibility of administrator individual differences affecting the scoring of the instrument; (b) the error rate associated with the instrument; and (c) the problems inherent in combining the risk factors effectively.

\section{Dependent Measures}

\section{Participants’ Dangerousness Beliefs}

Participants' beliefs regarding the defendant's dangerousness were measured at three separate times: first, after reading a summary of the case and the defendant's 
criminal history; second, after reading the expert testimony on the dangerousness of the defendant; and third, after reading the effective cross-examination. At each of these junctures, participants' beliefs concerning dangerousness were assessed by a yes/no decision on dangerousness. Participants then indicated their confidence in that decision on a scale ranging from 1 (not very confident) to 10 (very confident). An index of participants' dangerousness decisions was then created by multiplying decision, coded 1 (yes, defendant is dangerous and should be executed) and -1 (no, defendant is not dangerous and should not be executed) by confidence scores. Thus, the endpoints of the dangerousness index ranged from 10 (extremely confident defendant is dangerous) to -10 (extremely confident defendant is not dangerous).

\section{Basis of Participants’ Decisions on Dangerousness}

With the exception of the first dangerousness evaluation (which was made prior to the presentation of expert testimony), after completing the dangerousness assessments, participants indicated the relevant weight of factors they felt contributed to their dangerousness decisions. Participants provided estimates of the percentage that expert testimony, the defendant's past offenses, and the present offense contributed to their estimates of the defendant's dangerousness. Participants were instructed that the percentage they assigned to each of the three categories should add up to $100 \%$.

\section{Participants' Perceptions of the Expert}

Participants also provided their opinion of the quality of the expert testimony. Participants were asked "How influential do you feel the expert was?', "How scientific do you feel the expert was?", "How credible do you feel the expert was?", and "How confident do you feel the expert was?" Each of the four questions was rated on a scale of 1 (not very) to 10 (very). Finally, participants were thanked, debriefed, and dismissed.

\section{RESULTS}

\section{Dangerousness Ratings}

The main dependent measures of interest were participant's dangerousness assessments following the presentation of expert testimony and cross-examination (time 2 and time 3). Although participants were randomly assigned to conditions, it is possible that initial group differences (time 1) regarding perceptions of the defendant's dangerousness existed. As a result, a two-way (processing mode (PM): rational versus experiential $) \times($ expert testimony: clinical versus actuarial versus HCR)) analysis of covariance (ANCOVA) was performed on time 1 scores, with participants' support for the death penalty entered as a covariate. ${ }^{10,11}$ The results

\footnotetext{
${ }^{10}$ Two participants did not complete the dangerousness assessments, and are excluded from these analyses.

${ }^{11}$ Support for the death penalty was entered as a covariate because it was possible that any initial differences in dangerousness assessments might be due in part to individual differences regarding support for the death penalty.
} 
indicated a significant effect for the death penalty support covariate, $F(1,153)=20.49, p<0.01$. In addition, there was a main effect for expert testimony $(F(2,153)=3.54, p<0.05)$, with participants in the HCR group viewing the defendant as less dangerous than participants in the clinical or actuarial groups $(M=-1.02 ; 1.63 ; 1.89$, respectively). Because initial group differences were identified, time 1 scores were treated as a covariate in subsequent analyses. ${ }^{12}$

A repeated measures ANCOVA was then performed on the dangerousness $x$ confidence composite. Responses on dangerousness measures at time 2 and time 3 were entered as within-subjects variables. PM and expert testimony were betweensubjects factors, and time 1 ratings of dangerousness were used as a covariate. The results indicated a significant effect for the covariate of time 1 dangerousness ratings $(F(1,153)=271.82, p<0.01)$. As a result, relevant covaried means are reported throughout the rest of the paper and in the accompanying table. There was also a significant main effect for time $(F(1,153)=27.46, p<0.01)$, with dangerousness ratings higher immediately after expert testimony $(M=2.67)$ than following crossexamination of that testimony $(M=0.75)$, indicating that the cross-examination was effective. Several interactions were significant, including an interaction between the time (time 2 versus time 3 ) and time 1 covariate ratings $(F(1,153)=4.13$, $p<0.05)$. There was also a significant interaction between time and PM $(F(1,153)=4.58, p<0.01)$, with rational participants viewing the defendant as more dangerous than experiential mode participants immediately following the expert's testimony ( $M=3.03$ and 2.32 , respectively), but with experiential participants attributing a greater level of dangerousness to the defendant than rational participants after the testimony was refuted in cross-examination $(M=1.21$ and 0.29 , respectively).

Most importantly, the effects were qualified by a significant three-way (time)$\times(\mathrm{PM}) \times($ expert testimony) interaction $(F(2,153)=3.66, p<0.03)$. As can be seen in Table 1 , after the expert testimony was refuted during cross-examination,

Table 1. The effects of expert testimony and PM on time 2 (post-expert testimony) and time 3 (postcross-examination) dangerousness decisions

\begin{tabular}{|c|c|c|c|c|}
\hline \multirow[t]{2}{*}{ PM } & \multirow[t]{2}{*}{ Time } & \multicolumn{3}{|c|}{ Expert testimony } \\
\hline & & Clinical & Actuarial (VRAG) & HCR-20 \\
\hline \multicolumn{5}{|c|}{ Experiential } \\
\hline & Time 2 & $2.54(0.90)$ & $2.50(0.93)$ & $1.93(0.87)$ \\
\hline & Time 3 & $2.72(0.87)$ & $0.09(0.90)$ & $0.82(0.84)$ \\
\hline \multicolumn{3}{|c|}{ Rational } & $3.51(0.93)$ & $1.23(0.93)$ \\
\hline & Time 3 & $-0.02(0.94)$ & $1.52(0.91)$ & $-0.62(0.91)$ \\
\hline
\end{tabular}

Higher numbers indicate greater dangerousness ratings. Standard deviations are presented in parentheses.

\footnotetext{
${ }^{12}$ However, as death penalty ratings influenced time 1 perceptions of defendant dangerousness, and time 1 ratings were used as a covariate in analysis of time 2 and time 3 scores, death penalty ratings were not used in later statistical analyses. It is worth noting that significant effects reported later in this paper remained significant when death penalty ratings were entered as a covariate.
} 
participants' ratings of defendant dangerousness dropped in every condition except for the experiential mode-clinical testimony group (post-expert testimony $M=2.54$; post-cross-examination $M=2.72$ ). An examination of the responses for the experiential group indicates that following cross-examination clinical expert testimony participants were more likely to view the defendant as dangerous $(M=2.72)$ than participants exposed to actuarial $(M=0.09)$ or HCR$20(M=0.82)$ expert testimony. A planned contrast revealed that the difference between the clinical testimony group and the other two groups was significant $(t(153)=2.11, p<0.05)$. Several additional planned contrasts indicated that within the experiential condition cross-examination significantly reduced the impact of actuarial testimony $(t(153)=2.54, p<0.05)$, but not the impact of clinical testimony $(t(153)=0.20, p>0.84)$ or HCR-20 testimony $(t(153)=1.26, p>0.20)$. The fact that cross-examination did not significantly reduce the impact of HCR-20 testimony is most likely due to the minimal impact this type of testimony had on participants in the first place, leading to lower dangerousness ratings than those of clinical and actuarial participants (although not significantly so, $p>0.44$ ).

However, when participants were induced to think rationally, crossexamination was effective at reducing dangerousness ratings for the clinical testimony group (time $2 M=4.29$; time $3 M=-0.02$ ), $t(153)=4.39, p<0.01$ ). Several additional planned contrasts indicated that cross-examination also significantly reduced the impact of actuarial testimony $(t(153)=2.11, p<0.05)$ and HCR-20 testimony $(t(153)=2.00, p<0.05)$. In contrast to experiential participants who were most likely to find the defendant dangerous when clinical testimony had been presented, rational participants rated the defendant as most dangerous after the actuarial based testimony $(M=1.5)$ compared with clinical $(M=-0.02)$ or HCR-20 $(M=-0.62)$ testimony $(t(153)=2.22, p<0.05)$. Importantly, a planned contrast indicated that the dangerousness ratings of clinical participants in the rational condition were significantly lower than in the experiential condition $((M=-0.02$ and 2.72 , respectively), $t(153)=2.89, p<0.01))$. HCR-20 expert testimony led to the lowest estimates of dangerousness in the rational group. As with experiential participants, the weak effects of HCR-20 testimony following cross-examination were due to the minimal influence of this information initially. Indeed, for time 2 dangerousness ratings, HCR-20 group estimates were significantly lower than actuarial or clinical group estimates, $(t(153)=3.16, p<0.01)$. Perhaps the fact that the HCR-20 approach combines both clinical and actuarial testimony makes the ultimate product a watered down version of each, and consequently makes it less persuasive. This issue is addressed in greater detail in the discussion section.

The most central results of the study are the jurors' time 3 dangerousness ratings of the defendant, because they reflect participants' final decisions in the case. As evident in Figure 1, experiential participants were most influenced by clinical testimony, and rational participants were most influenced by actuarial testimony. When HCR-20 data is removed from the analyses (to better replicate the conditions used by Krauss and Sales (2001), which this work is based upon) an ANCOVA (with time 1 ratings entered as a covariate) showed a significant two-way interaction between testimony and processing mode $(F(1,104)=4.15, p<0.05)$ with time 3 ratings supporting this trend (see Table 2 ). 


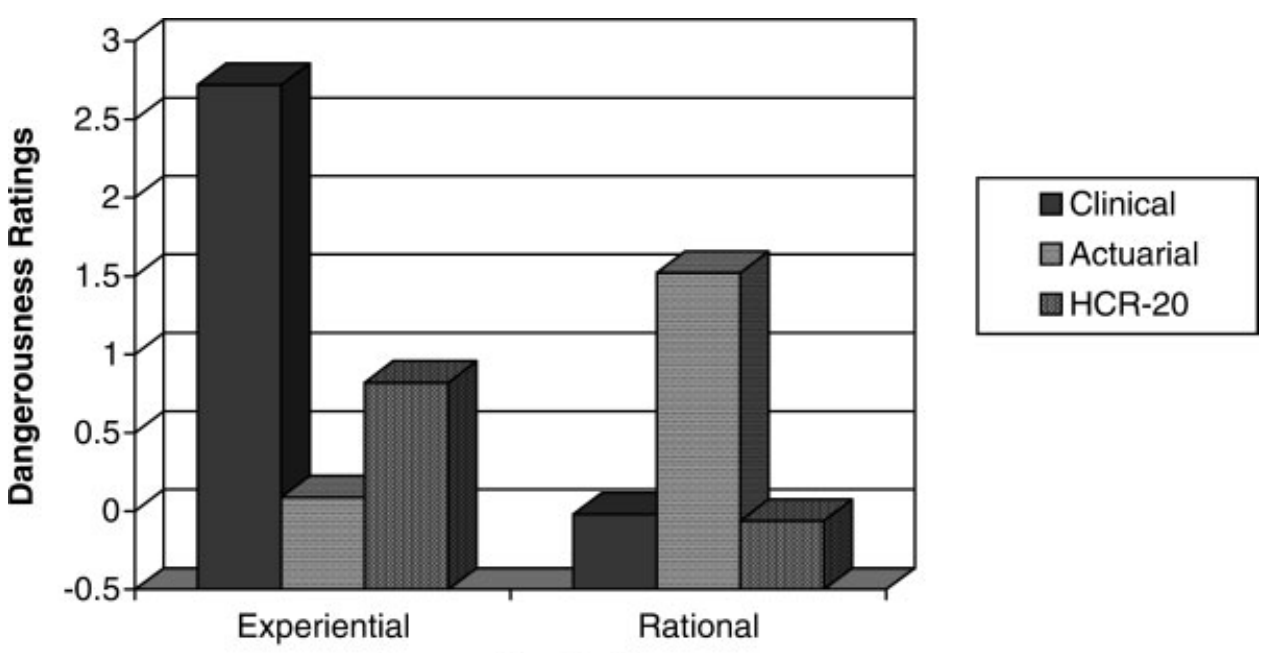

\section{Processing Mode}

Figure 1. Effects of expert testimony and PM on final dangerousness ratings (time 3).

Table 2. The effects of expert testimony (clinical versus actuarial) and PM on time 3 (post-cross-examination) dangerousness decisions

\begin{tabular}{llc}
\hline PM & \multicolumn{2}{c}{ Expert testimony } \\
\cline { 2 - 3 } & Clinical & Actuarial (VRAG) \\
\hline Experiential & $3.41(0.97)$ & $0.78(1.02)$ \\
Rational & $0.68(1.04)$ & $2.12(0.98)$ \\
\hline
\end{tabular}

Higher numbers indicate greater dangerousness ratings. Standard deviations presented in parentheses.

\section{Estimates of the Influence of Present Offense, Past Offense, and Expert Testimony Factors on Dangerousness Assessments}

A $2(P M) \times 3$ (expert testimony) multivariate analysis of variance (MANOVA) was performed on the weight mock jurors believed they assigned to the present offense, past offense, and expert testimony in their dangerous ratings at time $2 .{ }^{13}$ There were no significant main effects or interactions for any of the dependent measures $(p>0.51)$. An identical MANOVA was performed on these dependent measures following cross-examination. Once again, there were no significant group differences on any of the measures $(p>0.59)$. These findings indicate that participants may not be aware of the extent to which they are influenced by expert testimony because, while their dangerousness ratings demonstrate that they were differentially influenced by the expert testimony conditions, their own ratings of their reliance on the different types of expert testimony indicate no such differences.

\footnotetext{
${ }^{13}$ Data from nine participants were dropped from this analysis because their estimate scores did not total to $100 \%$. The results do not change when these participants are included in the analysis.
} 


\section{Evaluation of the Quality of Expert Testimony}

A $2(\mathrm{PM}) \times 3$ (expert testimony) MANOVA was performed on participants' time 2 ratings of how influential, scientific, and credible they felt the expert testimony was, and how confident they felt the expert was. A significant multivariate effect emerged for type of testimony (Wilks' lamda, $F(8,306)=4.33, p<0.01$ ). When evaluating how scientific the expert testimony was, clinical group participants felt their expert testimony was less scientific $(M=5.14)$ than participants in the actuarial $(M=6.17)$ or HCR-20 $(M=6.08)$ groups $(F(2,156)=3.56, p<0.05)$. No other individual or multivariate main effects or interactions were significant.

A $2(P M) \times 3$ (expert testimony) MANOVA was also performed on the same four dependent measures taken at time 3 . Once again, a significant multivariate effect emerged for type of testimony (Wilks' lamda, $F(8,306)=3.98, p<0.01$ ). As with time 2 measures, when evaluating how scientific the expert testimony was, clinical group participants felt the testimony was less scientific $(M=3.94)$ than participants in the actuarial $(M=5.33)$ or HCR-20 $(M=5.36)$ groups $(F(2,156)=6.04, p<0.01)$. No other individual or multivariate main effects or interactions were significant. Thus, it appears that jurors were aware that personal opinion testimony was less scientific in nature than testimony employing the VRAG or HCR-20 instruments.

\section{DISCUSSION}

This study was primarily conducted to better understand findings of previous research regarding the effects of expert testimony on perceptions of defendant dangerousness (Krauss \& Lee, 2003; Krauss \& Sales, 2001), and whether they could be reversed by inducing a rational model of processing in jurors. This previous research has shown clinical testimony to be more persuasive than actuarial testimony, despite the overall inferiority of clinical testimony in predicting violence (Borum, 1996; Gardner et al., 1996; Mossman, 1994; Quinsey et al., 1998). According to cognitive-experiential self-theory (CEST), this pattern of results may be due to the relative influence of experiential over rational information processing. CEST maintains that the experiential mode is a default way of processing information, because it is less effortful and more efficient. When the experiential mode is primarily operative, individuals often rely upon limited but intuitively appealing information to make judgments. Individuals typically ignore probabilistic and other statistically oriented information, and make decisions based on gut-level hunches, even though they are aware that such judgments are not completely rational. In contrast, rational processing leads individuals to think more abstractly and analytically. Judgments are more complex, and individuals are receptive to statistically oriented information. Consequently, we predicted that mock jurors would demonstrate the typical findings regarding the persuasive superiority of clinical testimony if they were in a more experiential mindset. However, we predicted that the influence of clinical testimony would be reduced if jurors were first oriented toward a more rational processing mode, leading actuarial testimony to be more persuasive. This effect was thought to be especially likely when stimulus materials that had consistently demonstrated a bias in favor of clinical expert testimony in previous mock jurors experiments were used. 
As expected, the results indicated that clinical testimony led to higher ratings of defendant's dangerousness in the experiential mode condition. However, the effects of clinical testimony were significantly reduced when a rational processing mode was induced in participants. It is interesting that the effects did not emerge on judgments immediately following the presentation of expert testimony. Rather, they emerged after cross-examination. One possible explanation for this is that, although participants were influenced by the initial expert testimony in general, rational participants were better able to integrate the contradictory information contained in the crossexamination, and adjusted their verdicts accordingly. Of note to support this possibility is the fact that all cross-examinations used a rational or logic oriented approach to attack the expert testimony presented in each condition. Alternatively, clinical testimony may have been so appealing to experiential mode participants that belief perseverance effects occurred (Anderson, Lepper, \& Ross, 1980). As a result, experiential participants became highly resistant to contradictory cross-examination information. This explanation, however, while consistent with other research outside the jury decision-making context, is a post hoc explanation and additional research will need to be completed to further examine this issue.

The results for the groups exposed to expert testimony based on HCR-20 assessments indicate that this instrument is not persuasive to mock jurors. This surprising finding is especially troubling given that a plurality of mental health scholars characterize such testimony as superior to both clinical and actuarial models (Webster et al., 1997; Hart, 1998). The poor performance of the HCR20 in all conditions suggests that this testimony may be generally less influential than either clinical or actuarial expert testimony, and that, as past research on actuarial expert testimony demonstrated, jurors may be biased against a more scientifically accurate type of expert testimony. ${ }^{14}$ Juror bias against this form of testimony could lead to unjust outcomes for defendants when more scientifically valid guided professional judgment expert testimony is weighed less heavily by jurors than less accurate clinical expert testimony.

\section{Study Limitations}

As with many experimental studies on jury decision-making, the external and ecological validity of the findings are potentially limited because college students were used instead of actual jurors, testimony was conveyed using a written transcript, and jurors did not engage in deliberations. ${ }^{15}$ However, in a review

\footnotetext{
${ }^{14}$ It should be noted that a recent pilot study conducted by the authors comparing the effects of HCR-20 testimony to clinical and actuarial testimony in the absence of any processing mode manipulations revealed a similar pattern of means. Clinical and actuarial testimony led to higher dangerousness ratings then HCR-20 testimony.

${ }^{15}$ It is also not clear whether these experimental conditions accurately mimic how such testimony is presented in practice. One reviewer noted that is much more common for clinical expert testimony to be used by the prosecution to show that the defendant is dangerous while statistical base rate expert testimony is often presented by the defense to show that the defendant is unlikely to be dangerous (Cunningham and Reidy, 1999; 2002). Unfortunately, no research currently exists examining the types of expert testimony most commonly proffered in Texas death penalty proceedings (Reidy \& Cunningham, 1999). Future research should systematically explore the content of expert testimony in capital sentencing, and (if relevant) investigate what effects following pro-prosecution clinical expert testimony with pro-defense statistical expert testimony might produce.
} 
examining the effects of different samples of mock jurors (college students versus representative jurors) and different media of trial presentation (i.e. written transcript versus audio-tape versus videotape), Bornstein (1999) reported that these factors typically have minimal or no impact on participants' behaviors. Further, Lieberman and Miethe (manuscript submitted for publication) have recently shown that college students and representative jurors drawn from a local jury pool had virtually identical perceptions of a variety of scientific evidence presented by expert witnesses. Most importantly, past research that has directly examined the effects of actuarial and clinical testimony on defendant dangerousness decisions, using the same stimulus materials as presented in this study (Krauss \& Lee, 2003; Krauss \& Sales, 2001) but in a videotaped format, has shown that participants' responses to clinical and actuarial testimony are quite robust, replicate across different populations and different settings (classroom versus actual courtroom), and do not vary as a function of whether jurors are allowed to deliberate or not.

\section{Trial Procedure Implications}

Although the goal of this study was to manipulate processing mode in order to better understand when participants would utilize different types of expert testimony, it is possible that courts or attorneys might want to encourage jurors to adopt either experiential or rational processing modes during a trial. Lieberman (2002) notes that attorneys could encourage experiential processing through the use of specific language, vivid photographs, videotaped presentations, or other exhibits (Belli, 1982; Mauet, 1992; Sannito \& McGovern, 1993) designed to arouse emotions. In contrast, if an attorney wanted to minimize the impact of experientially based judgments, and encourage rational processing, he or she would be advised to avoid these types of exhibits, and emphasize statistically oriented evidence, such as laboratory reports. Attorneys might try to capitalize on such approaches during opening and closing statements. In addition, during voir dire, attorneys could try to identify jurors who have a greater natural inclination for either experiential or rational processing. Individual difference measures have been developed and validated in several CEST studies (e.g. Epstein, Pacini, Denes-Raj, \& Heier, 1996; Pacini et al., 1998). Many attorneys are likely aware that there may be benefits to employing or avoiding an emotional appeal with jurors. However, attorneys may not be aware of the complexity of the interaction between emotional arousal and various aspects of the case.

If courts were concerned that jurors were giving insufficient weight to actuarial testimony, procedural instructions akin to cautionary instructions could be developed. Obviously, the approaches used in this study to activate rational and experiential processing (using math problems and creative drawing exercises) would not be utilized in the courtroom. However, other research on the effects of CEST has shown that processing mode can be successfully manipulated by giving participants direct instructions to think rationally and analytically, or to go with their "gut-level" feelings (Lieberman, 2002; Lieberman \& Greenberg, manuscript submitted for publication; Simon et al., 1996). Thus, it should be possible to develop effective procedural instructions in this regard.

In future research, it would be useful to explore the impact of various types of emotionally oriented testimony on juror decisions. For example, victim impact 
testimony provided by the State may be so emotionally arousing that it fosters very powerful experiential processing in jurors. This might be particularly important in death penalty cases, because the prosecution has the opportunity to present such evidence during the initial portion of the sentencing phase of a trial. Alternatively, if the defense presented powerful mitigating factors for a defendant's behavior that were emotionally oriented in nature (e.g. the defendant's long history of being physically and psychologically abused) it might be more difficult for jurors to adopt a rational mindset.

Future research should also examine factors other than processing mode that may influence dangerousness testimony effectiveness. For example, if jurors thought an expert was a "hired gun" (Cooper \& Neuhaus, 2000), because the expert frequently testified, was paid handsomely for his or her services, or had poor credentials, would juror confidence in clinical testimony be reduced? Would actuarial based-testimony be more immune to a cross-examination designed to discredit the credentials of the expert because the dangerousness assessment is more scientifically valid and less dependent upon personal opinion? Thus, the results of the present study may have a number of implications for the procedures used by courts and attorneys when dangerousness assessments are made.

\section{Summary}

The results of this study are consistent with those that would have been predicted by CEST. Jurors who received an experiential mode manipulation found the clinical expert testimony more influential in their decisions than the other two types of expert testimony presented while jurors who received a rational model manipulation found the actuarial expert testimony more compelling than other types of expert testimony.

Additionally, the ineffectiveness of expert testimony based on a guided clinical judgment instrument (the HCR-20) to influence jurors' decisions in this study suggests that greater attention needs to be paid by researchers to the impact of different types of expert testimony on juror decisions. Although this testimony's poor performance in one study of mock jurors is not sufficient grounds for largescale concern, it is troubling that this testimony performed so poorly in comparison with other types of expert testimony utilized. It is even more problematic because guided professional judgment instruments have become all the more common and touted as superior to both clinical and actuarial techniques (Webster et al., 1997). Future research will need to explore whether these types of assessment, which are considered state of the art or best clinical practice by some scholars (Hart, 1998), are viewed as less persuasive or influential than other assessment methodologies by actual jurors.

\section{REFERENCES}

Anderson, C. A., Lepper, M. R., \& Ross, L. (1980). Perseverance of social theories: The role of explanation in the persistence of discredited information. Fournal of Personality and Social Psychology, 39, 1037-1049. 
Barefoot v. Estelle, No. 82-6080, 463 U.S.880 (S.Ct. 1983).

Belli, M. (1982). Modern trials. St. Paul, MN: West.

Bornstein, B. H. (1999). The ecological validity of jury simulations: Is the jury still out? Law and Human Behavior, 23, 75-91.

Borum, R. (1996). Improving the clinical practice of violence risk assessment. American Psychologist, 51, 945-956.

Brekke, N., \& Borgida, E. (1988). Expert psychological testimony in rape trials: A social-cognitive analysis. Fournal of Personality and Social Psychology, 55, 372-386.

Brief for the American Psychiatric Association as Amicus Curiae in Support of Petitioner, in Barefoot $v$. Estelle, No. 82-6080, 463 U.S. 880 (1983).

Chaiken, S. (1987). The heuristic model of persuasion. In M. P. Zanna, J. M. Olson, \& C. P. Herman (Eds.), Social influence: The Ontario symposium (Vol. 5, pp. 3-39). Hilsdale, NJ: Erlbaum.

Cooper, J., Bennett, E., \& Sukel, H. (1996). Complex scientific testimony: How do jurors make decisions? Law and Human Behavior, 20, 379-395.

Cooper, J., \& Neuhaus, I. M. (2000). The "hired gun" effect: Assessing the effect of pay, frequency of testifying, and credentials on the perception of expert testimony. Law and Human Behavior, 24, 149171.

Cunningham, M., \& Reidy, T. (1998). Integrating base rate data in violence risk assessment at capital sentencing. Behavioral Science and the Law, 16, 71-83. (citing S. B. McPherson, Psychological aspects of mitigation in capital cases (1996) (unpublished manuscript)).

Cunningham, M., \& Reidy, T. (1999). Don't confuse me with facts: Common errors in violence risk assessment at capital sentencing. Criminal fustice and Behavior, 26, 20-43.

Cunningham, M., \& Reidy, T. (2002). Violence risk assessment at federal capital sentencing: Individualization, generalization, relevance, and scientific standards. Criminal fustice and Behavior, 29, 512-537.

Cutler, B., Penrod, S., \& Dexter, H. (1989). The eyewitness, the expert psychologist, and the jury. Law and Human Behavior, 13, 311-332.

Denes-Raj, V., \& Epstein, S. (1994). Conflict between intuitive and rational processing: When people behave against their better judgments. Fournal of Personality and Social Psychology, 66, 819-829.

Donovan, S., \& Epstein, S. (1997). The difficulty of the Linda conjunction problem can be attributed to its simultaneous concrete and unnatural representation, and not to conversational implicature. Fournal of Experimental Social Psychology, 33, 1-20.

Douglas, K., Ogloff, J., Nicholls, T., \& Grant, I. (1999). Assessing risk for violence among psychiatric patients: The HCR-20 violence risk assessment scheme and the psychopathic checklist: Screening version. Fournal of Consulting and Clinical Psychology, 67, 917-930.

Douglas, K., \& Webster, C. (1999). The HCR-20 violence risk assessment scheme: Concurrent validity in a sample of incarcerated offenders. Criminal fustice and Behavior, 26, 3-19.

Edens, J., Petrila, J., \& Buffington-Vollum, J. (2001). Psychopathy and the death penalty: Can the psychopathic checklist - revised identify offenders who represent "a continuing danger to society"? Fournal of Psychiatry and Law, 29, 433-482.

Epstein, S. (1994). Integration of the cognitive and the psychodynamic unconscious. American Psychologist, 49, 709-724.

Epstein, S., \& Pacini, R. (1999). Some basic issues regarding dual-process theories from the perspective of cognitive-experiential self-theory. In S. Chaiken, \& Y. Trope (Eds.), Dual process theories in social psychology (pp. 462-483). New York: Guilford.

Epstein, S., Pacini, R., Denes-Raj, V., \& Heier, H. (1996). Individual differences in intuitive relative to analytical processing of information. Fournal of Personality and Social Psychology, 71, 390-405.

Faust, D., \& Ziskin, J. (1988). The expert witness in psychology and psychiatry. Science, 241, 31-35.

Gardner, W., Lidz, C., Mulvey, E., \& Shaw, E. (1996). Clinical versus actuarial predictions of violence in patients with mental illness. Fournal of Consulting and Clinical Psychology, 64, 602-609.

Goldberg, L. (1968). Simple models or simple process? Some research on clinical judgement. American Psychologist, 23, 483-496.

Grisso, T., \& Appelbaum, P. (1992). Structuring the debate about ethical predictions of future violence. Law and Human Behavior, 17, 482-485.

Grove, W., \& Meehl, P. (1996). Comparative efficiency if informal (subjective, impressionistic) and formal (mechanical, algorithmic) prediction procedures: The clinical-statistical controversy. Psychology, Public Policy, and Law, 2, 293-323.

Guy, L., \& Edens, J. (2003). Juror decision-making in a mock sexually violent predator trial: Gender differences in the impact of divergent types of expert testimony. Behavioral Science and the Law, 21, $215-237$.

Harris, G., Rice, M., \& Cormier, C. (2002). Prospective replication of the Violence Risk Appraisal Guide in predicting violent recidivism among forensic patients. Law and Human Behavior, 26, 377-394.

Hart, S. (1998). The role of psychopathy in assessing risk of violence: Conceptual and methodological issues. Legal and Criminological Psychology, 2, 338-341. 
Hart, S., Webster, C., \& Menzies, R. (1993). A note on portraying the accuracy of violence predictions. Law and Human Behavior, 17, 695-700.

Kahneman, D., \& Tversky, A. (1982). The simulation heuristic. In D. Kahneman, P. Slovic, \& A. Tversky (Eds.), Fudgment under uncertainty: Heuristics and biases (pp. 201-208). New York: Cambridge University Press.

Kansas v. Crane, 534 U.S. 407 (S.Ct. 2002).

Kansas v. Hendricks, 521 S.Ct. 2072 (1997).

Krauss, D. (2004). Adjusting risk of recidivism: Do judicial departures worsen or improve recidivism prediction under the Federal Sentencing Guidelines? Behavioral Science and the Law, in press.

Krauss, D., \& Lee, D. (2003). Deliberating on dangerousness and death: Jurors' ability to differentiate between expert actuarial and clinical predictions of dangerousness. International fournal of Law and Psychiatry, 26, 113-137.

Krauss, D., \& O'Connor, M. (2002). Legal update: Update on sexual predators laws. American Psychology-Law Society, Division 41. American Psychological Association Newsletter, 22, 1-3.

Krauss, D., \& Sales, B. (2001). The effects of clinical and scientific expert testimony on juror decisionmaking in capital sentencing. Psychology, Public Policy, and Law, 7, 267-310.

Lavin, M., \& Sales, B. (1998). Moral justifications on the limits of expert testimony. In S. Ceci, \& H. Hembrook (Eds.), Expert witnesses in child abuse cases (pp. 59-81). Washington, DC: American Psychological Association.

Litwack, T. (2001). Actuarial versus clinical assessments of dangerousness. Psychology, Public Policy, and Law, 7, 409-443.

Lieberman, J. D. (2002). Head over the heart or heart over the head? Cognitive-experiential self-theory and extra-legal heuristics in juror decision-making. Fournal of Applied Social Psychology, 32, 2526-2553.

Loftus, E. (1986). Ten years in the life of an expert witness. Law and Human Behavior, 10, 241-263.

Mauet, T. (1992). Fundamentals of trial techniques. Boston, MA: Little, Brown.

McNeil, D., Sanders, D., \& Binder, R. (1998). The relationship between confidence and accuracy in clinical predictions of psychiatric patients' potential for violence. Law and Human Behavior, 25, 655671.

Melton, G., Petrila, J., Poythress, N., \& Slobogin, C. (1997). Psychological evaluations for the courts: A handbook for mental health professionals and lawyers. New York: Guildford.

Monahan, J. (1981). The clinical prediction of violent behavior. Beverly Hills, CA: Sage.

Monahan, J. (2003). Violence risk assessment. In I. B. Weiner (Series Ed.), \& A. Goldstein (Vol. Ed.), The handbook of psychology: Forensic psychology (Vol. 11, pp. 527-542). Hoboken, NJ: Wiley.

Monahan, J., \& Steadman, H. (1994). Violence and mental disorder: Developments in risk assessment. Chicago, IL: University of Chicago Press.

Monahan, J., Steadman, H., Silver, E., Appelbaum, P., Robbins, P., Mulvey, E., Roth, L., Grisso, T., \& Banks, S. (2001). Rethinking risk assessment: The MacArthur study of mental disorders and violence. New York: Oxford University Press.

Morling, B., \& Epstein, S. M. (1997). Compromises produced by the dialectic between self-verification and self-enhancement. Fournal of Personality and Social Psychology, 73, 1268-1283.

Mossman, D. (1994). Assessing predictions of violence: Being accurate about accuracy. Fournal of Consulting and Clinical, 62, 783-792.

O’Connor v. Donaldson, 422 U.S. 563 (S.Ct. 1975).

Otto, R. (1992). Predictions of dangerous behavior: A review and analysis of the second generation research. Forensic Reports, 5, 103-133.

Pacini, R., Muir, F., \& Epstein, S. (1998). Depressive realism from the perspective of cognitiveexperiential self-theory. Fournal of Personality and Social Psychology, 74, 1056-1088.

Petty, R., \& Caccioppo, J. (1986). Communication and persuasion: Central and peripheral routes in attitude change. New York: Springer.

Quinsey, V., Harris, G., Rice, M., \& Cormier, C. (1998). Violent offenders: Appraising and managing risk. American Psychological Association: Washington, DC.

Rice, M., \& Harris, G. (1995). Violent recidivism: Assessing predictive validity. Fournal of Consulting and Clinical Psychology, 63, 737-748.

Rogers, R., Bagby, R., \& Chow, M. (1992). Psychiatrists and the parameter of expert testimony. International fournal of Law and Psychiatry, 15, 387-396.

Rogers, R., Bagby, R., Crouch, M., \& Cutler, B. (1990). Effects of ultimate opinions on juror perceptions of insanity. International fournal of Law and Psychiatry, 13, 225-232.

Sannito, T., \& McGovern, P. J. (1993). Courtroom psychology for trial lawyers. 1993 cumulative supplement. New York: Wiley.

Schuller, R., \& Vidmar, N. (1992). Battered wife syndrome evidence in the courtroom: A review of the literature. Law and Human Behavior, 16, 273-291.

Showalter, C. (1990). Psychiatric participation in capital sentencing procedures: Ethical considerations. International fournal of Law and Psychiatry, 13, 261-280. 
Shuman, D., Whitaker, E., \& Champagne, A. (1994). An empirical examination of the use of expert witnesses in the courts - part II: A three part study. Furimetrics, 34, 193-208.

Simon, L., Greenberg, J., Harmon-Jones, E., Solomon, S., Pyszczynski, T., Arndt, J., \& Abend, T. (1996). Terror management and cognitive experiential self theory: Evidence that terror management occurs in the experiential system. Fournal of Personality and Social Psychology, 72, 1132-1146.

Smith v. State, 898 S.W.2d 838 (Tex. Crim. App. 1995).

Sundby, S. (1997). The jury as critic: An empirical look at how capital juries perceive expert and law testimony. Virginia Law Review, 83, 1109-1188.

Texas Defender Service. (2004). Deadly Speculation: Misleading Texas capital juries with false predictions of future dangerousness. http: //www.texasdefender.org/DEADLYSP.PDF.

Tversky, A., \& Kahneman, D. (1974). Judgment under uncertainty: Heuristics and biases. Science, 185, $1124-1131$.

Tversky, A., \& Kahneman, D. (1982). Judgments of and by representativeness. In D. Kahneman, P. Slovic, \& A. Tversky (Eds.), Fudgment under uncertainty: Heuristics and biases (pp. 84-100). New York: Cambridge University Press.

Wainwright v. Witt, 469 U.S. 419 (S.Ct. 1985).

Webster, C., Douglas, K., Eaves, D., \& Hart, S. (1997). HCR-20: Assessing risk for violence. Burnaby, British Columbia: Simon Fraser University, Mental Health, Law, and Policy Institute. 